\title{
Los signos iconográficos del reconocimiento público de la Enfermería en España: su importancia y significación
}

\section{Iconographic signs of public recognition of Nursing in Spain: their relevance and significance}

\section{Sinais iconográficos de reconhecimento público da enfermagem na Espanha: sua relevância e significado \\ José Antonio Ávila Olivares ${ }^{1}$}

${ }^{1}$ Enfermero y antropólogo. Doctor por la Universidad de Alicante. Presidente del Consejo de Enfermería de la Comunidad Valenciana (CECOVA).

Cómo citar este artículo en edición digital: Ávila Olivares, J.A. (2014)

Los signos iconográficos del reconocimiento público de la Enfermería en España: su importancia y significación. Cultura de los Cuidados (Edición digital) 18, 38. Disponible en: http://dx.doi.org/10.7184/cuid.2014.38.12>

Correspondencia: Correo electrónico: ja.avila@wanadoo.es

Recibido: 11/12/2013; Aceptado: 2401/2014

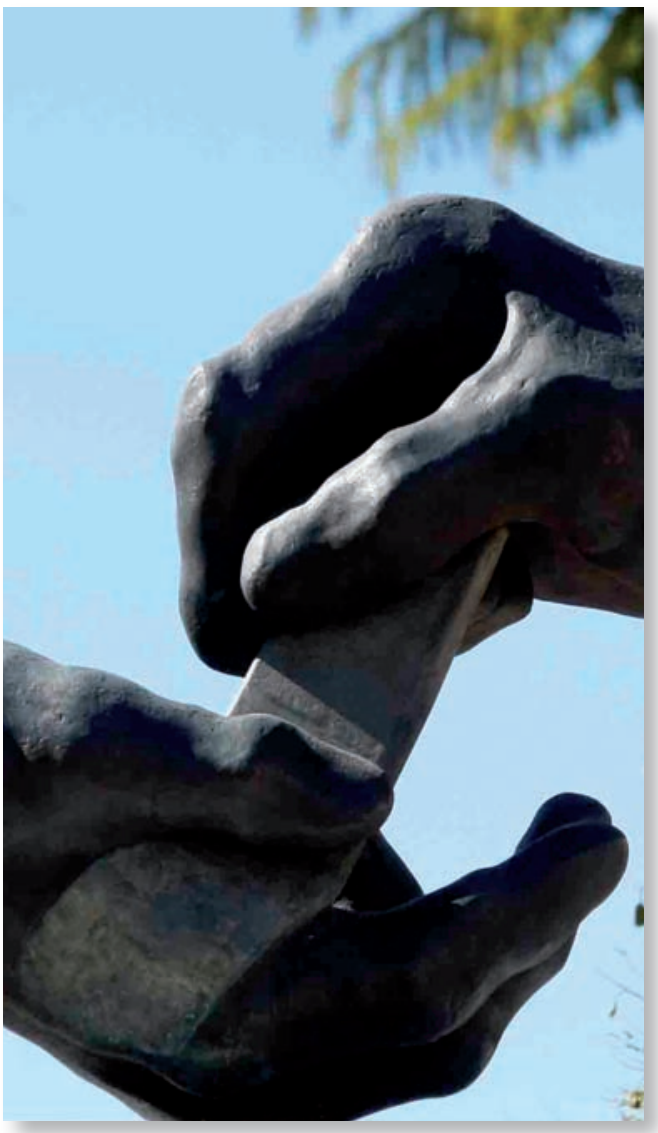

\section{ABSTRACT}

Iconographic signs (statues, monoliths and monuments; dedication of streets or other public spaces; philatelic issues, etc..) to express public recognition to nurses and nursing, are realizations arising mainly from virtually the last years of twentieth century. However, they have had to date they deserve consideration in the study of the History of Nursing.

This paper seeks to identify those in Spain, cataloging and describing, analyzing with the help of semiotics the degree of perception of their messages and how these signs can be considered relevant and appropriate to achieve the objectives.

Keywords: Iconography nurse, social Recognition of Nursing, Monuments of Nursing, Professional Associations.

\section{RESUMO}

Sinais iconográficos (estátuas, monólitos e monumentos; dedicação de ruas ou outros espaços públicos emissões filatélicas, etc.) para 
expressar o reconhecimento público para os enfermeiros e auxiliares de enfermagem, são realizações decorrentes principalmente de praticamente os últimos anos de século XX. No entanto, eles tiveram até agora eles merecem consideração no estudo da História da Enfermagem.

Este trabalho busca identificar aqueles em Espanha, catalogar e descrever, analisar com a ajuda da semiótica, o grau de percepção de suas mensagens e como esses sinais podem ser considerados relevantes e adequados para atingir os objectivos

Palavras-chave: enfermeira Iconografia, reconhecimento social da Enfermagem, Monumentos de Enfermagem, associações profissionais.

\section{RESUMEN}

Los signos iconográficos (estatuas, monolitos y monumentos; dedicación de calles u otros espacios públicos; emisiones filatélicas, etc.) para manifestar el reconocimiento público a las enfermeras y a la Enfermería, son realizaciones en su mayoría surgidas prácticamente a partir de los últimos años del pasado siglo XX. Sin embargo, no han tenido hasta la fecha la consideración que se merecen en el estudio de la Historia de la Enfermería.

En este trabajo se trata de identificar los existentes en España, catalogarlos y describirlos, analizando con el auxilio de la semiótica el grado de percepción de sus mensajes y en qué medida estos signos pueden considerarse pertinentes y adecuados para lograr los objetivos propuestos.

Palabras clave: Iconografía enfermera, Reconocimiento social de la Enfermería, Monumentos de Enfermería, Colegios Profesionales.

\section{INTRODUCCIÓN}

Los signos iconográficos notorios que hallamos en España, erigidos en reconocimiento y exaltación de las enfermeras y de la profesión de Enfermería, inclinan por su interés y significación a tratar de conocer, a la luz de la semiótica, en qué grado los profesionales en particular y la profesión en general son percibidos a través de ellos como un valor de excelente consideración con claras connotaciones de solvencia profesional, cercanía, aprecio y gratitud. Términos que, para en lo sucesivo simplificar lo más posible, designaremos de una manera global y manteniendo su grado superlativo, con el concepto "reconocimiento público". La relevancia y constancia de estos signos en Alicante fue lo que me estimuló para hacer extensivo su estudio al resto de España y así poder ofrecer una aportación más amplia en este ámbito.

\section{OBJETIVO}

El objetivo principal de trabajo es el identificar: ¿Cuáles son los signos iconográficos en nuestro país, erigidos como homenaje a enfermeras o a la profesión de Enfermería? ¿De qué género y clase son? y ¿En qué medida podemos considerarlos elementos pertinentes para comunicar el reconocimiento social que preconizan?

\section{ESTADO DE LA CUESTIÓN}

En la actualidad, las fuentes escritas son el principal material que se emplea en las investigaciones históricas, incluidas las relacionadas con la Enfermería, sin embargo hay otras manifestaciones humanas que también han demostrado su importancia y valor histórico a pesar de no haberse materializado a través de la escritura (Calvo 1994). Un ejemplo de ello es la iconografía, cuyo empleo viene cobrando un creciente interés y demostrando su utilidad 
para los estudiosos de la historia de la profesión enfermera, empleando el material iconográfico para realizar trabajos históricos desde diferentes perspectivas de estudio.

Todo indica que, hasta la fecha, los investigadores han dado preferencia a los estudios que demuestran que "el material iconográfico constituye una fuente para la historia de la enfermería”. Siles (1994a), en primer lugar, determina, en línea con la teoría científica de la cultura de Malinowski, no sólo la idoneidad de las fuentes iconográficas, sino su relevancia indispensable tanto en el método históricoetnográfico como en el biográfico. y posteriormente Núñez et al. (2004b) va a reafirmar esta aportación. En esta misma línea, Magdalena Santo Tomás $(1996,1997)$ sostiene que los signos iconográficos han de ser considerados como fuentes historiográficas válidas, puesto que "deben entenderse también como algo que comporta un significado que sobrepasa lo visual". Con su exposición sobre la interpretación iconográfica, según el esquema de Panofski (1. Descripción preiconográfica, 2. Análisis iconográfico, 3. Interpretación iconográfica), asegura que los resultados obtenidos vienen a complementar el método sociológico, incrementando su efectividad hermenéutica, otorgándole la consideración de documentos históricos.

Siles (1999), señala que cualquier tema, objeto o personaje relacionado con la enfermería en cualquiera de sus épocas y variantes puede ser estudiado iconográficamente. Incide en el "enfoque sociológico" dentro del proceso de análisis iconográfico y diseña un proceso sintético para las diversas formas de realización: “1. Datación, procedencia y estilo artístico.2. Identificación del tema iconográfico. 3. Contextualización histórica. Interpretación iconográfica."
Para el profesor Siles (2011), es una forma de análisis de contenido, que tiene identidad propia y que puede considerarse tanto como una fuente como un método de indudable valor para la historia de la enfermería.

La fotografía y el cine, de gran interés sociológico como fuentes gráficas auxiliares en el proceso hermenéutico, han sido seleccionadas por Lasarte (2000) y Monge (2001) para aportar su particular visión de la historia de la enfermería (S. XIX y S. XX). Por lo que respecta al cine, identificando y clasificando géneros y películas para un estudio histórico y transcultural (Siles et al. (1994 b) y considerado como género histórico documental y biográfico ( $\mathrm{Si}$ les, 2009).

$\mathrm{Y}$ ya en aspectos concretos de las funciones de enfermería, referidos a los cuidados (Núñez et al., 2004a) y a la relación de ayuda (Núñez et al. 2008a) vienen a demostrar, que la iconografía, refleja "de forma holística" las realidades de estos dos aspectos, además de constituir una fuente para la historia de la enfermería, confirmando la validez del material icnográfico para avanzar en este conocimiento histórico. Unas investigaciones que la llevaron a defender su tesis doctoral utilizando la iconografía para realizar una aportación histórica cultural de los cuidados de salud desde la perspectiva de la enfermería. Núñez del Castillo (2008b).

Así pues, como vemos, todas las aportaciones mencionadas se centran en el plano sociológico-etnográfico de las fuentes (modos operatorios, métodos, instrumental, etc.), sin inferir de los signos la imagen corporativa de la enfermería como profesión. En este sentido, los trabajos sobre la iconografía enfermera abordando el estudio de los monumentos o signos iconográficos de otra naturaleza, sea con carácter monográfico o meramente tan- 
gencial, no son muchos los publicados hasta la fecha. Vamos a enumerar los más significativos, si bien algunos tocan muy tangencialmente el aspecto que motiva este estudio.

$M^{a}$ Francisca Casas Martínez y Ma Teresa Miralles Sangro publicaron en 2001 su trabajo Monumento a las enfermeras de la Cruz Roja de Astorga. En él, tras una detallada y bien documentada descripción de cómo estaba organizada la atención sanitaria en los dos bandos de la Guerra Civil española y, en concreto la formación, destinos y funciones asistenciales de las enfermeras, pasan a referir el fatídico destino de tres enfermeras astorganas que fueron fusiladas en Somiedo (Asturias) por el $5^{\circ}$ Regimiento de Milicias Populares, el 29 de octubre de 1936. Conocidas localmente como las "Mártires de Somiedo", la villa de Astorga, en su honor, el 28 de junio de 1948, erige para acoger sus restos un monumento funerario en la Catedral y rotula con ese mismo nombre una de sus calles.

En 2005, Ma Teresa Miralles Sangro y Marta Durán Escribano publican La enfermera en el monumento madrileño (1908-1936), estudio que, partiendo del objetivo de analizar "la influencia de la enfermera a través de su presencia en el monumento público o privado, como señal de reconocimiento social, [...] examinar los monumentos femeninos de Madrid, tratando de descubrir aquellos que representan la imagen de la enfermera”. Pero, en la demarcación cronológica y geográfica establecida no les fue posible hallar más que el monumento a la Duquesa de la Victoria, Carmen de Angloti y Mesa, Vocal Presidenta de Distrito de la Asamblea Central de la Cruz Roja Española. Situado a la entrada del madrileño Hospital Central de la Cruz Roja, conocido como Hospital de San José y Santa Adela (Avda. de Reina Victoria, no 24).
Por lo que se refiere al estudio de las emisiones filatélicas españolas relacionadas de algún modo con la enfermería ha sido pionero Antonio Manuel Ballesteros Álvaro con La Enfermería Española y su historia en la filatelia (2006). En cuanto a la Enfermería y las enfermeras en la filatelia mundial hay que reseñar las siguientes obras: Salvador Luna Gálvez, con su trabajo La Enfermería y la Filatelia (2004), Historia de la Enfermería. Reflejo en la filatelia mundial (2008) de José Eugenio Guerra González y La Enfermería a través de los sellos (2008) de María Teresa Miralles Sangro.

\section{MATERIAL Y MÉTODO}

El proceso heurístico seguido se ha centrado en fuentes primarias documentales del Colegio de Enfermería de Alicante, prensa corporativa de los Colegios de Alicante, Madrid, Murcia y Cáceres, así como los periódicos locales siguientes: Información y Las Provincias (Alicante), La Verdad y La Opinión (Murcia), Extremadura (Cáceres) e Ideal (Almería).

Por lo que respecta al método, nos hemos valido de elementos de análisis específicos de la iconografía y de la semiótica para determinar la carga comunicativa de cada uno de los signos analizados, considerando estas disciplinas como la más adecuada para esta tarea. La semiótica, como disciplina que se ocupa del estudio de los procesos mediante los cuales algo se utiliza como representación de otra cosa, sustituyendo a esa cosa en algún sentido, provee un sólido instrumental teórico para el abordaje de los signos iconográficos de las enfermeras y de la Enfermería que aquí nos proponemos estudiar. 


\section{RESULTADOS}

Sobre los monumentos y los signos iconográficos de otra naturaleza hallados durante el proceso heurístico, hemos de reseñar los siguientes, analizados por orden cronológico:

\section{Monumentos}

1.- Monumento a la Duquesa de la Victoria (Madrid, 1925)

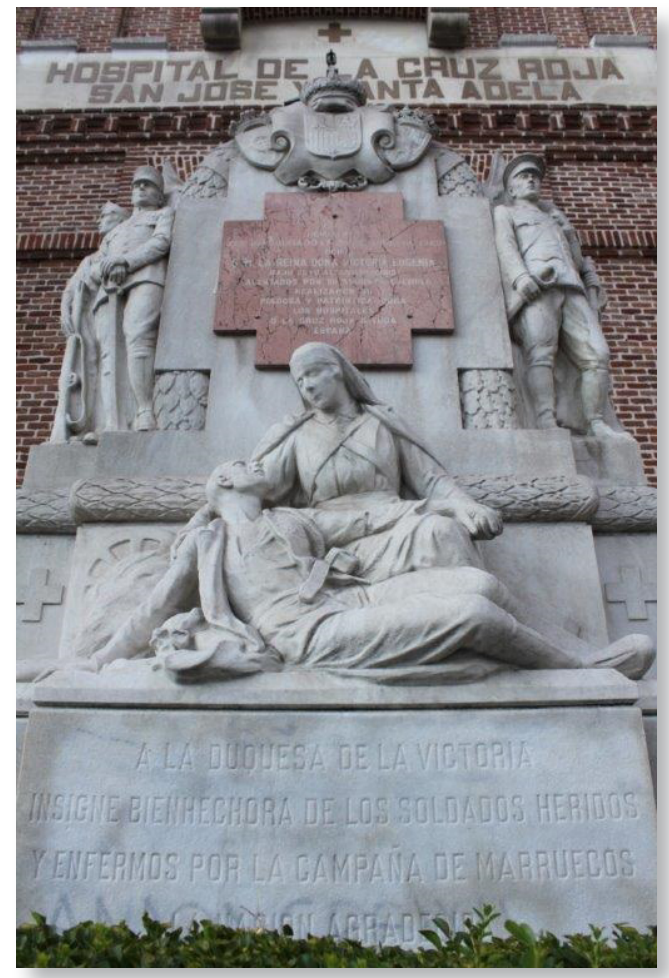

Monumento erigido en 1925, obra del escultor asturiano Julio González Pola y García (1865-1929) exclusivamente dedicado "A la Duquesa de la Victoria, bienhechora de los soldados heridos y enfermos por la campaña de Marruecos, la Nación agradecida”, así se indica en la gran lápida de mármol del frontal de su pedestal.

Concebido con un gran sentido escénico, en su cuerpo central, un grupo escultórico de tamaño natural compuesto por la figura tallada de la Duquesa, con uniforme de enfermera de la Cruz Roja, y un soldado herido al que asiste. Su figura es la de una sanitaria sentada que auxilia al herido en batalla que está tendido. Sostiene la Duquesa la cabeza del soldado que reposa sobre su pierna y brazo derecho, al tiempo que con su otra mano sujeta la mano izquierda del combatiente exánime, tratando de confortarle. En los ojos de éste se refleja un intenso dolor y el rostro de la Duquesa de la Victoria manifiesta una cálida expresión de piedad.

Un signo iconográfico que sometido a un somero análisis semiológico, podemos observar cómo por tratarse de una persona tan importante y estar el signo tan centrado en un sujeto concreto (la Duquesa, con sus rasgos personales fielmente esculpidos) su significado acorta su comprensión hasta individualizarla.

Añade confusión y distorsiona aún más el mensaje del monumento el que en lugar preeminente haya una gran lápida de fino mármol, con el color y la forma del emblema de la Cruz Roja, en la que está grabado lo siguiente: Este monumento fue inaugurado el 29 de junio de 1925 por S. M. la Reina Victoria Eugenia bajo cuyo alto patrocinio alentados por su augusto ejemplo realizaron su piadosa y patriótica obra los Hospitales de la Cruz Roja de toda España. Se enaltece a los Hospitales de la institución pero no se menciona a las enfermeras.

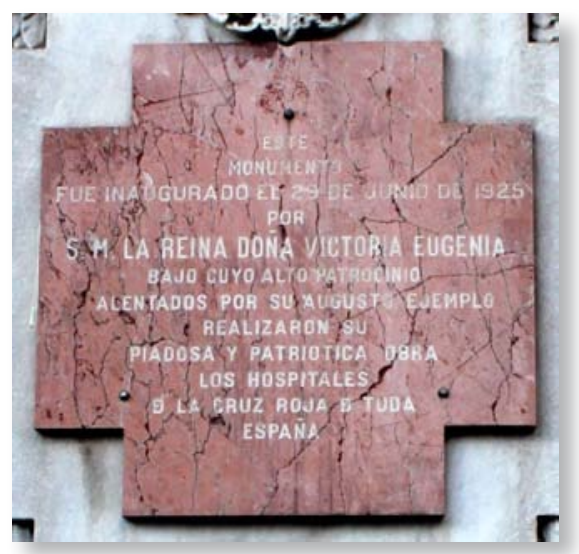


2.- Monumento a las enfermeras de la Cruz Roja de Astorga (1948)

El monumento, adosado a una de las paredes laterales de templo catedralicio astorgano, estéticamente no puede calificarse como un acierto, si bien en la España de 1948 no era la estética un valor al que se le prestara demasiada consideración. Además, siendo construido por suscripción popular, en un tiempo marcado por la carencia y la precariedad económica, el montante recogido debió de ser forzosamente exiguo.

Así lo describen las autoras de este estudio: "El monumento es de piedra y arranca del suelo. En la parte superior hay una gran cruz a medio relieve, partida en el extremo inferior del brazo vertical por un escudo de España. La cruz se apoya en el conjunto de tres lápidas de mármol. En cada una de ellas y grabadas en letra dorada, los nombres de las enfermeras: Octavia Iglesias, en la superior, M. Pilar Gullón, en la inferior derecha y Olga P. Monteserín en la inferior izquierda. En el centro de las tres lápidas, una cruz roja. El conjunto descansa en la base rectangular del monumento en la que una inscripción, también en mármol del mismo color reza: Enfermeras de la Cruz Roja muertas en Somiedo en octubre de 1936"

$\mathrm{Al}$ ser un monumento funerario religioso situado en el interior de un templo, naturalmente su entidad de signo iconográfico viene determinada por su función conmemorativa centrada exclusivamente en el dramático hecho mortuorio de las personas concernidas. El reconocimiento social está evidenciado con total coherencia del signo y su significado, no hay distorsión ninguna, pues lo que hace patente es el gran impacto emocional que la muerte de estas enfermeras en una acción de guerra supuso para sus conciudadanos y su ferviente deseo de mantener viva perennemente la memoria de su trágico destino.
Naturalmente, ante el carácter conmemorativo de este monumento in memoriam de un hecho dramático concreto y de unas personas concretas, difícilmente podemos considerar que su significación alcance a ser asociado y redundar en el prestigio social de las enfermeras y la Enfermería españolas en general.

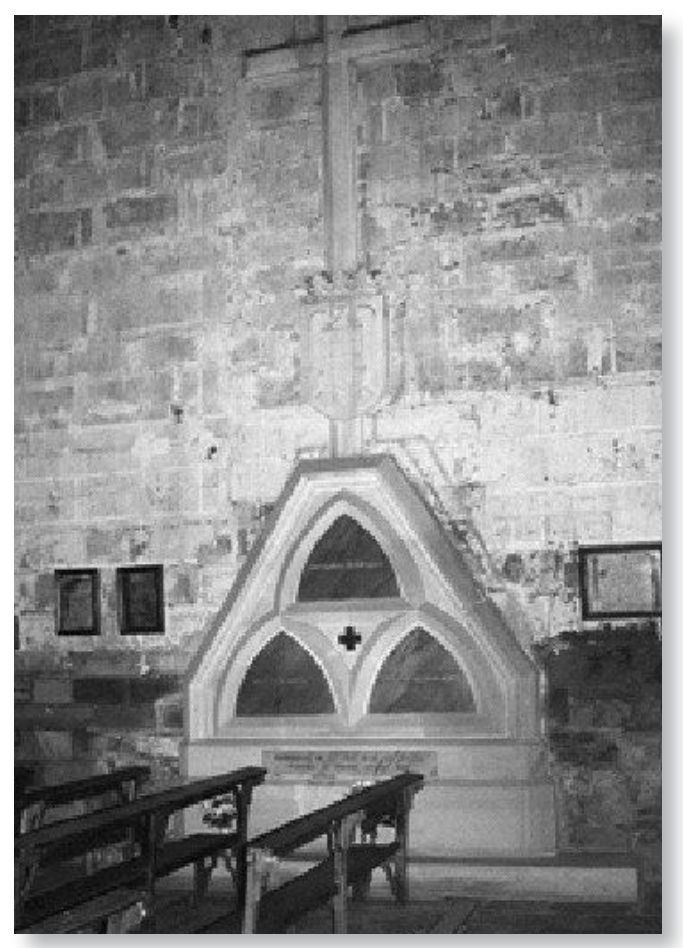

3.- Homenaje a la Enfermería (Madrid, 1999)

En los jardines que ornan la entrada del Hospital Montepríncipe, en Boadilla del Monte (Madrid), se erigió el 12 de mayo de 1999, coincidiendo con el Día de la Enfermería, el primer monumento expresamente dedicado a homenajear la Enfermería en un espacio público. Así lo proclama la placa situada en el bloque de granito de la Sierra de Guadarrama que constituye el pedestal sobre el que se asienta la estatua de bronce representación de esta profesión. Para ello se eligió como signo 
iconográfico la figura de una enfermera anónima, ataviada con el uniforme de trabajo, cofia incluida, y los elementos necesarios para desarrollar su labor asistencial (fonendoscopio y tablilla de anotaciones), fundida en bronce y a tamaño natural.

En la placa adosada al pedestal figura la leyenda: "Homenaje a la Enfermería. Monumento inaugurado el 12 de mayo de 1999, día mundial de la enfermería, por $\mathrm{D}^{\mathrm{a}}$ Margarita de Borbón, duquesa de Soria”.

Tanto por su destacado emplazamiento, junto a la entrada del Hospital, como por su fuste, elección de motivo y su dedicatoria, cumple adecuadamente la función de homenaje y reconocimiento a las enfermeras y la Enfermería. Existe una coherencia entre el signo y el mensaje que transmite, resaltando la figura de la enfermera en actitud de estar trabajando, aisladamente y puesta de relevancia, sin otros elementos que pudieran perturbar con ruidos la comprensión de lo que se quiere comunicar. Mensaje que se refuerza con la dedicatoria de homenaje de la placa.

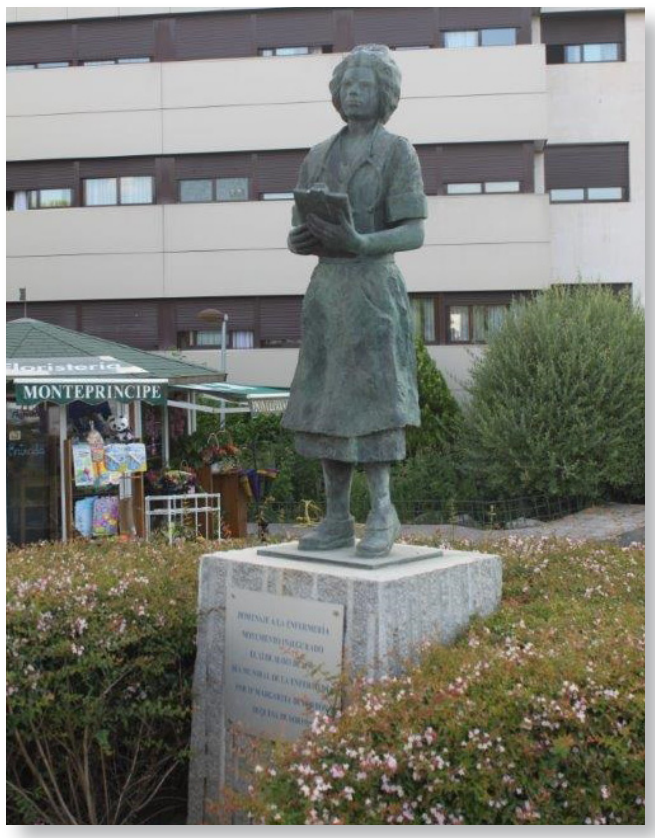

4.- Monumento a la enfermera (Cáceres, 2007)

En Cáceres, el 9 de marzo de 2007, coincidiendo con la festividad de San Juan de Dios, patrón de la Enfermería, el entonces alcalde la ciudad, José María Saponi, inauguraba, junto al presidente del Colegio de Enfermería cacereño, Isidro Nevado, un monumento en un espacio público y céntrico con el que la ciudad extremeña dejó patente y reconoció la labor de "abnegación, esfuerzo y sacrificio" de un colectivo enfermero que, según sus propias palabras, tiene en la provincia casi 2.500 profesionales ${ }^{1}$.

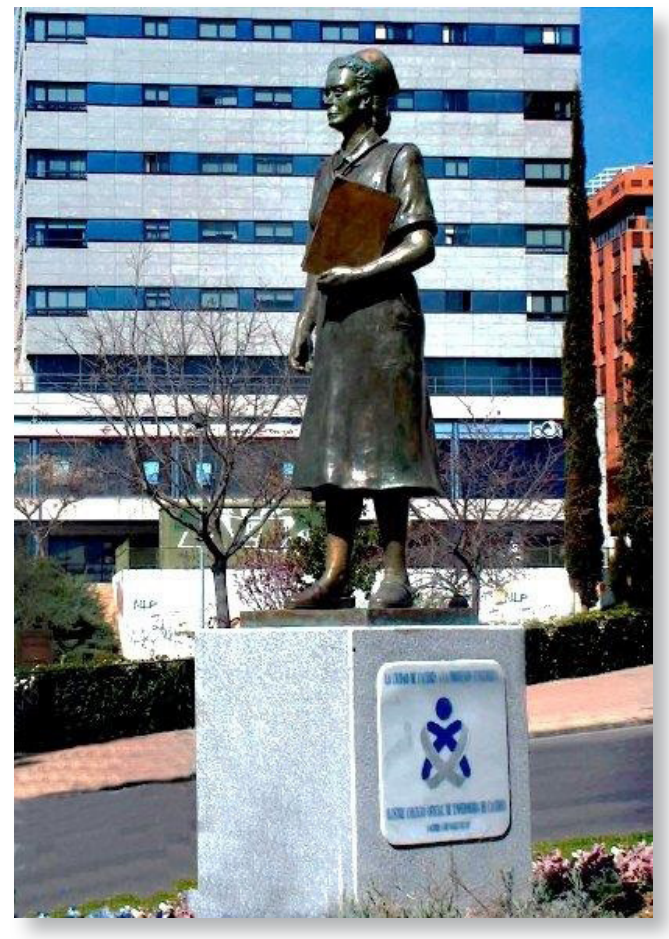

El monumento presenta la figura de bronce de una enfermera anónima, de pie, de un metro de altura y ataviada con un uniforme

\footnotetext{
${ }^{1}$ Información recogida por el diario Extremadura, edición de Cáceres, del día 9 de marzo de 2007 y Diario Enfermero de fecha 14 de marzo de 2007. (Publicación electrónica del Consejo General de Enfermería)
} 
de los años 30 del pasado siglo. La escultura es obra del artista Antonio Fernández, está colocada sobre un pedestal de piedra que la eleva a un metro del suelo, ornada por parterre floral, situado en la Avda. de Isabel Moctezuma, próximo a una rotonda y a escasos metros del Colegio de Enfermería.

\section{5.- Homenaje a la Enfermería (Murcia,} 2009)

Con motivo de celebrarse el Centenario del Colegio de Enfermería, el 12 de mayo de 2009 se inauguró en Murcia, en la zona peatonal de acceso al Hospital Reina Sofía, el monumento "Homenaje a la Enfermería". El alcalde, Miguel Ángel Cámara, agradeció al Colegio, en la persona de su presidente, Diego Gutiérrez Gambín, "la generosa donación" de esta escultura, obra del afamado artista local Miguel Llamas que ha reproducido el motivo principal en una plancha de acero pulido y una cabeza tratada con sustrato de manganeso que al aplicarla al bronce se queda con su color dorado. "La curvatura aporta un gesto de inclinación hacia delante, como para atender a otro, un gesto maternal, de cuidar de otro, lo propio de la profesión enfermera -según su autor-, y las aspas quieren significar las tiras cruzadas sobre el torso que antiguamente llevaban las capas del uniforme de las enfermeras". Tiene

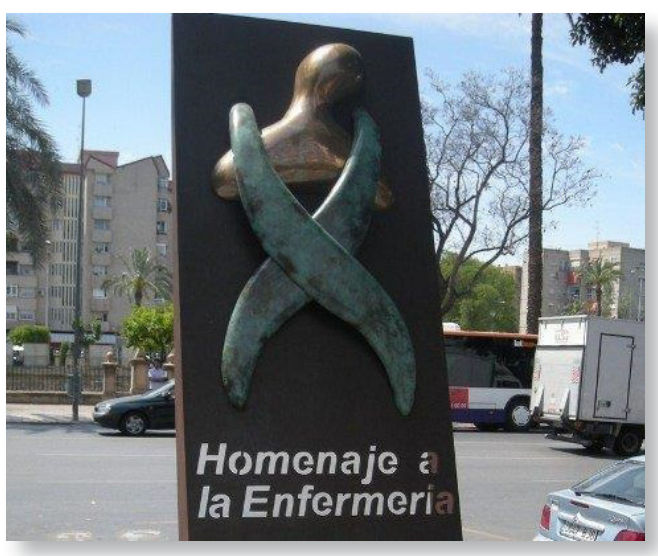

una altura de 3,70 metros y un peso de 2.500 kilogramos.

En el acto de inauguración el presidente de la Comunidad, Ramón Luis Valcárcel aseguro que "se produce un punto de coincidencia permanente entre la Enfermería murciana y el Ayuntamiento de Murcia que se dan la mano para embellecer las calles de la ciudad con este monumento", llamando a homenajear y a recordar la dedicación y el buen trabajo de todo el colectivo profesional de Enfermería y de su Colegio en los cien años de historia y en el futuro.

Monumento moderno, abstracto, con significante y significado convergentes y en absoluta coherencia, lo cual optimiza la efectividad comunicativa del mensaje y refuerza su pregnancia.

6.- Monolito en honor de los profesionales de Enfermería (Almería, 2010)

El Colegio de Enfermería de la provincia de Almería, con motivo de su 125 aniversario, instó a la Corporación municipal de la capital a erigir un monolito en honor "de todos los profesionales de Enfermería, los pasados y los presentes", en palabras de la presidenta del Colegio, María del Carmen Pozo. La sugerencia fue aprobada y el Ayuntamiento de Almería determinó su colocación a la entrada de las Consultas Externas del Hospital Torrecárdenas.

El monumento consiste en un bloque de una piedra ornamental de color rojo (Travertino Rojo) que se extrae en las canteras de localidad de Alhama de Almería, que presenta gran profusión de bandeados y oquedades. Se trata de una caliza formada en condiciones de agua dulce, compacta y a la vez muy porosa y de una dureza superior al resto de los travertinos españoles. Este bloque, con unas dimensiones de $200 \times 60 \times 30$, presenta un 
rebaje en el que se ubica una lámpara, tallada en mármol blanco de Macael que rememora a Florence Nightingale, la "Dama de la lámpara", icono internacional de la Enfermería. La llama de la lámpara es de mármol ornamental amarillo. En una placa figura una inscripción que define la profesión Enfermería: "Protegiendo la salud de los almerienses y garantizando la seguridad de sus pacientes desde una práctica y ética competente". Fue inaugurado el 11 de junio de 2010.

A la concepción simbólica de este monumento, en principio adecuada en su significación, el objeto representado y materiales escogidos para su realización, sólo cabe oponer la objeción del escaso conocimiento que en España tiene la gente corriente de la labor y de la persona de la célebre enfermera británica Florence Naightingale y de la historia de la lámpara, lo que hace disminuir la intensidad del mensaje a nivel popular.

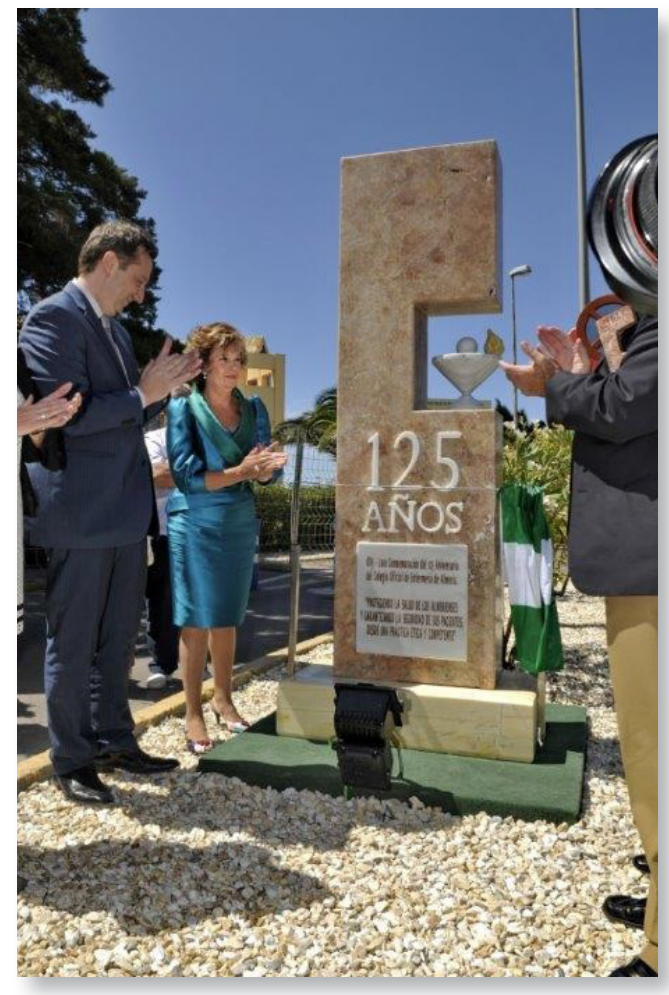

7.- Escultura representativa en honor de la Enfermería

El Colegio de Enfermería alicantino consiguió el firme compromiso de la alcaldesa, Sonia Castedo, de erigir en un espacio público de la ciudad de Alicante una escultura en honor de la profesión de Enfermería. Compromiso que se hizo realidad el 16 de febrero de 2011 con su solemne inauguración, que vino a rubricar el cierre de actos del Centenario del Colegio.

La obra, realización de José Díaz Azorín, es una escultura en bronce, sobre pedestal de piedra blanca, que reproduce dos manos, una de persona joven que toma a la de un mayor. La una ayuda a la otra, clara evocación de los cuidados de Enfermería, en homenaje y reconocimiento a la meritísima labor que desempeñan las enfermeras en la prestación de cuidados. La escultura mide 2,5 metros de longitud por 1,60 de alto y está colocada sobre un pedestal de hormigón de $3 \mathrm{~m}$. de altura. Se ubica en el centro de la zona ajardinada de la Avda. del Historiador Vicente Ramos de Alicante. (Imagen 8).

En el acto inaugural, la presidenta del Colegio, Belén Payá, expreso su deseo de que dicho monumento sirviera para "ofrecer una imagen que vaya más allá de lo referente a la relación de las enfermeras con el dolor humano por el trato con los enfermos, consiguiendo que dicha imagen se proyecte sobre la prestación de cuidados y el apoyo a las personas sanas, a través de la prevención y la promoción de la salud".

La elección de las manos como imagen representativa de la función enfermera en general se adecúa perfectamente con el mensaje que se pretende expresar. Las manos acarician, saludan, manifiestan afecto, curan, lavan, masajean, dan o toman, sostienen, levantan, sujetan, aplauden... Gestos gratos y loables, todos 
ellos, cuando se trata de manos amigas, manos tendidas, manos afectuosas. En este sentido, toda esta fuerza evocadora, al ser aplicada a la Enfermería, magnifica y engrandece la nobleza y dignidad de su función y del trabajo de quienes son dispensadoras de la misma, las enfermeras. Claro ejemplo de adecuación excelente de significante y significado.

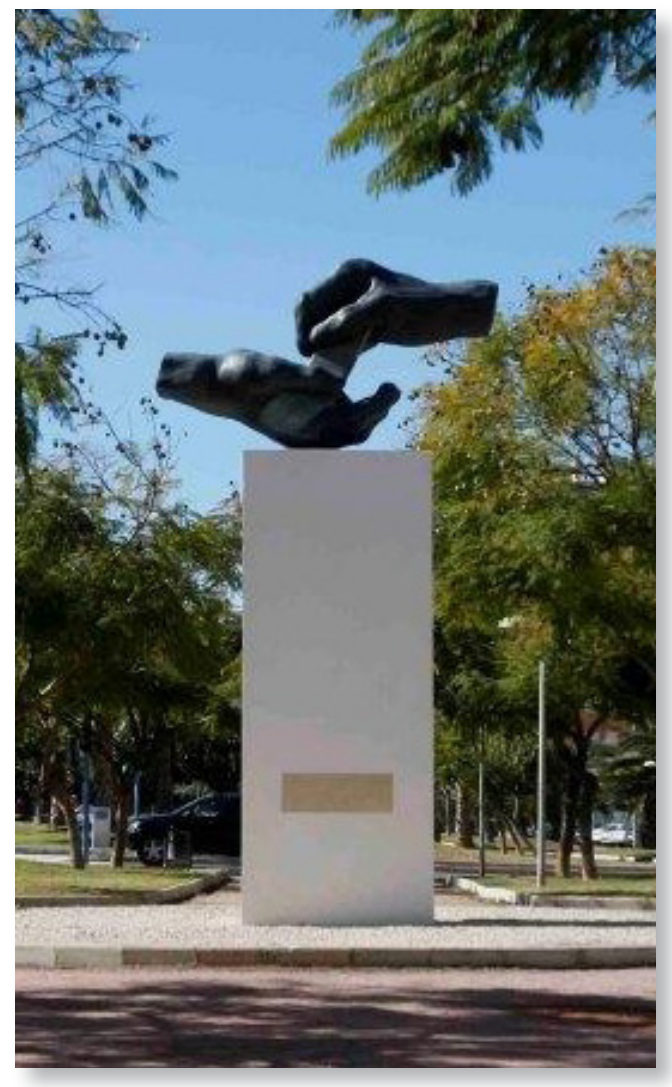

\section{Emisiones filatélicas}

Una acción singular utilizada universalmente para mostrar reconocimiento público a personajes y acontecimientos relevantes ha sido dedicarles sellos de correo. En España este tipo de homenajes se viene realizando desde 1850, fecha en que se emitió el primer sello. En el caso que nos ocupa, las realizaciones especí- ficamente creadas otorgando protagonismo a la Enfermería han sido las siguientes:

1.- El 8 de mayo de 2002, en el marco de las XIII Jornadas Nacionales de Supervisión de Enfermería, celebradas en Madrid, el presidente de Correos y Telégrafos, Alberto Núñez Feijoo, hizo la presentación de un sello conmemorativo del 175 aniversario del nacimiento del Dr. Federico Rubio y Galí, presentándolo como un homenaje a la Enfermería porque, según sus palabras, "los sellos tienen que rendir homenaje a las instituciones y a las profesiones, y la Enfermería se ha merecido este reconocimiento social por sus 150 años de historia"2.

Con una tirada de 1.200.000 ejemplares, se calculaba que el contacto visual del mismo alcanzara hasta los 9 millones de personas. Además, 200.000 filatélicos lo incluirían en sus colecciones. Es decir que el impacto se preveía como excepcional por su amplia difusión.

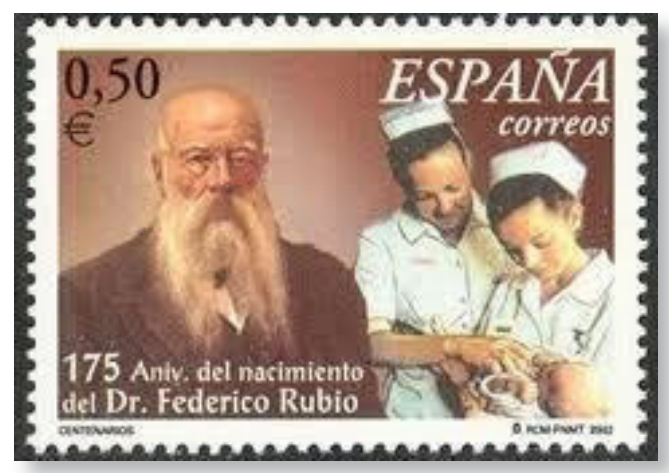

Pero ¿cuál era en realidad su mensaje? ¿El señalado por el presidente de Correos? ¿ $\mathrm{O}$, tal vez, confundía la realidad con los buenos deseos?

En el análisis semiótico hemos de tener muy en cuenta el diseño, las imágenes y su

${ }^{2} h t t p: / / w w w . m e d i c i n a t v . c o m / n o t i c i a s / c o r r e o s-p r e s e n t a-u n-$ nuevo-sello-con-una-tirada-de-1200000-que-homenajeaa-la-enfermeria-espanola-53761 (Consultado el 12 julio 2013) 
disposición en el espacio. El primer rango del sello lo ocupa el retrato del Dr. Rubio, a la izquierda y bajo la cifra 0,50 € del franqueo, en primer plano y a gran tamaño; resaltando su traje oscuro sobre el que se escribe en caracteres blancos: "175 Aniv. del nacimiento del D. Federico Rubio". Ambos elementos, -retrato y leyenda-, y la pose del médico, estática, con la mirada al frente, no dejan duda sobre a quien se pretende homenajear. Su cabeza aparece rodeada por un halo de luz que ensalza y dignifica su figura, como se suele representar a los santos en algunas estampas religiosas.

A la derecha, con menor rango, en plano medio y bajo el rótulo "España, Correos", se muestra a dos enfermeras anónimas, que mantienen en brazos a un recién nacido, ataviadas con sus cofias y batas blancas.

Cierto que el Dr. Rubio fue el creador en España de la primera escuela de enfermeras laicas (1896), pero esto no es conocido por todo el mundo. Lo que se representa en el sello no puede ser entendido como un homenaje a la Enfermería (como dijo el presidente de Correos, que erró también afirmando que la Enfermería cumplía 150 años). Lo que muestra claramente es el concepto trasnochado de significar a las enfermeras como auxiliares de los médicos, trabajando bajo sus órdenes y supervisión. Así pues, una clara distorsión del mensaje que se pretendía comunicar.

2.- Para mayor difusión de la conmemoración de su 150 aniversario, el Colegio de Enfermeras de Madrid, gestionó la emisión de un sello personalizado, encargando a $\mathrm{M}^{\mathrm{a}} \mathrm{Te}$ resa Miralles Sangro su diseño. Su emisión fue aprobada el 22 de febrero de 2012, tan sólo seis días después de ser registrada la solicitud del Colegio; la tirada inicial fue de 500 ejemplares, destinados al franqueo nacional, en formato vertical y dentado, con medidas de 28,8 x 40,9, presentado en pliegos de 25 sellos autoadhesivos troquelados.

La leyenda explícita, destacada y personalizada "Colegio de Enfermería de Madrid. 150 Aniversario. 1862-2012”, que acompaña a la imagen de una enferma uniformada, identifica y prestigia a la institución a quien está dedicada la emisión.

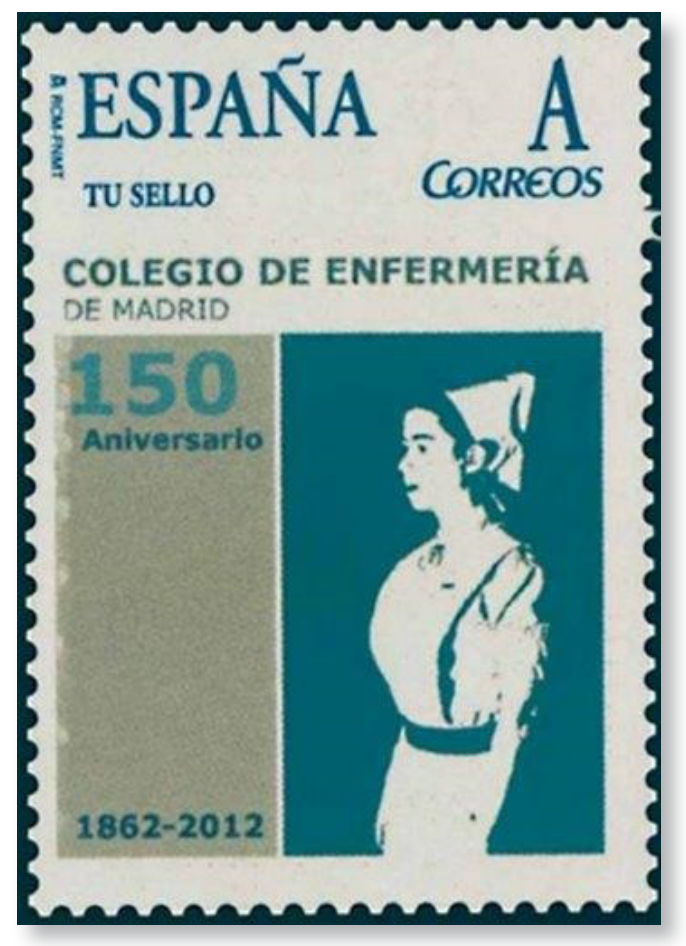

3.- En la misma línea, la Asociación Nacional Enfermería Salud Mental, también encargó a Ma Teresa Miralles la realización de los tramites frente a la sociedad estatal Correos y Telégrafos SA, para la emisión de un sello con motivo del 30 aniversario de la asociación. Así, en 2013 sale a la luz el sello conmemorativo, en el cual se recoge la siguiente inscripción “30 años cuidando", además de la alusión a la citada Asociación de Enfermería promotora. Los sellos son autoadhesivos y se presentan en pliegos de 25 sellos, producidos por la Fábrica Nacional de Moneda y Timbre. La tirada fue 
de 20 pliegos, y las medidas de los sellos son las habituales, 28,8 x 40,9 mm., siendo el valor de franqueo el equivalente a la carta ordinaria de ámbito nacional.

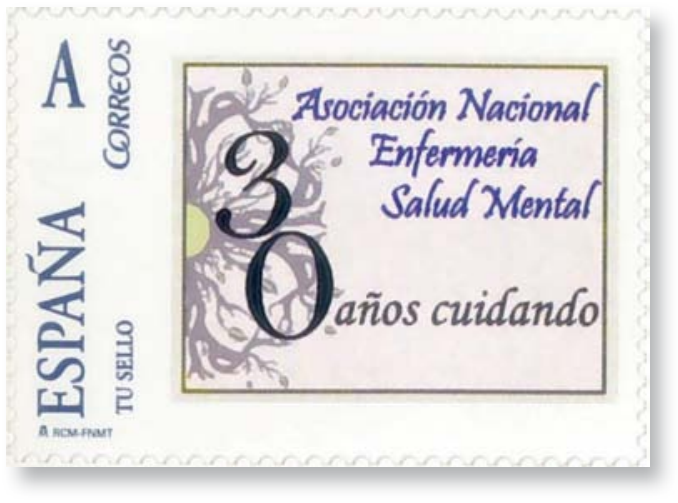

\section{Dedicación de espacios públicos}

En muchas ciudades españolas, para significar el reconocimiento público de la población a las enfermeras y a la Enfermería, se han rotulado calles $\mathrm{u}$ otros espacios públicos. Abundan las calles dedicadas a practicantes y matronas en pueblos y ciudades.

Hemos de señalar como significativo que, tras escrutar la prensa nacional, hemos hallado las siguientes informaciones referidas a la materia de éste nuestro estudio, todas ellas con una base común: haber sido propiciadas por la acción de los Colegios de Enfermería, estimulando a las Corporaciones locales a hacer manifestación pública del estado de opinión favorable y generalizado que la sociedad expresa sobre la calidad profesional de las enfermeras y su reconocimiento hacia la Enfermería, manifestándolo con signos iconográficos visibles en espacios públicos.

\section{1.- Calles dedicadas en la provincia de Alicante}

Este reconocimiento popular, por lo que respecta a las enfermeras, ha sido trasladado a las corporaciones y organismos provinciales y locales por la acción del Colegio de Enfermería alicantino, logrando de ellas que lo hiciera presente con signos icnográficos en espacios públicos de los respectivos municipios. Impulso secundado y potenciado por el CECOVA ${ }^{3}$. Por ello, a fecha de hoy, pueden los profesionales de Enfermería de la provincia de Alicante presumir de contar con un vasto catálogo de realizaciones que muestran la gratitud y la exaltación de la profesión en general y de los profesionales de las tres ramas que en su larga andadura histórica acabaron por vertebrar la actual Enfermería: practicantes, matronas, A. T. S. y enfermeras.

Una de las iniciativas del Colegio de Enfermería en la conmemoración de su centenario en 2009, fue precisamente la elaboración un callejero enfermero de la provincia. Es decir, identificar las calles que en los municipios alicantinos estaban dedicadas a los/as practicantes, matronas, enfermeras y ATS de todos los tiempos.

Para ello realizó una consulta por escrito solicitando respuesta a todos los Ayuntamientos de la provincia sobre la existencia de alguna calle a nombre de auxiliares sanitarios en sus ciudades, pueblos y pedanías. El censo provincial de municipios alicantinos está actualmente constituido por 141 núcleos de población que cuentan con corporación municipal y ayuntamiento propio, de los que administrativamente dependen en algunos casos numerosas pedanías y partidas.

El resultado que arrojó la encuesta fue de 28 vías urbanas, sean calles, plazas o parques, que llevan el nombre de alguna o alguno de los profesionales colegiados en su tiempo. De ese total, seis pertenecen a la capital, cuyo consistorio

${ }^{3}$ Consejo de Enfermería de la Comunidad Valenciana, organismo colegial autonómico en el que se integran los Colegios de Alicante, Castellón y Valencia. 
dedicó, a solicitud del Colegio, una plaza y una calle a dos ATS, Juan Pamblanco y Pascual Ruiz Galiano, respectivamente; una a una enfermera, Angelina Cevallos Quintanal; otra a una matrona, María de Gracia Cases, y dos a practicantes, Juan Caturla Gonsálvez y Vicente Blasco.

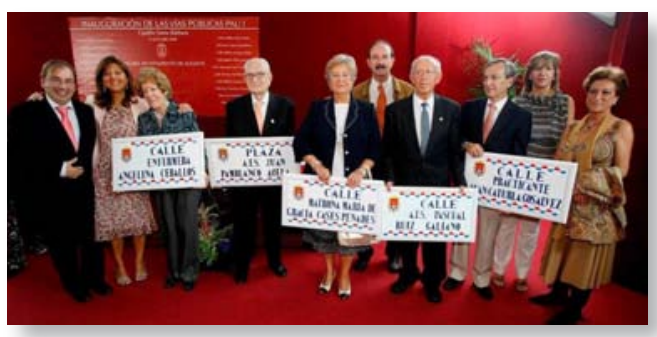

Años antes Vicente Mojica, poeta y practicante, y José Llopis, concejal y practicante, habían recibido idéntico honor por iniciativa del propio Ayuntamiento. En Santa Pola, merecieron el honor de inscribir sus nombres en el callejero municipal, tres enfermeros: un practicante, una matrona y otra profesional de la que no nos han podido aclarar su especialidad concreta, Margarita Bascuñana. En Crevillent, la calle Doña Pepita, perpetúa la memoria de la matrona Josefa Luna Corbo, queridísima en dicha villa. Un practicante tiene a su nombre en Tibi una calle y un parque, se trata de Miguel Mira Cremades. Y en Granja de Rocamora, se da el caso de que en el rótulo de la calle dedicada al practicante figura también su apodo, que resulta chocante y paradójico: Calle de Antonio Martínez "Boticario". En Petrel figura la calle de Pepita "La Comare", que ignoramos si es simple casualidad o se refiere a la misma "Doña Pepita" de Crevillent que hubiera ejercido anteriormente en esta localidad. El practicante Antonio Soriano Bri tiene calle en Daya Vieja y en Daya Nueva.

Por especialidad, se sitúan en cabeza los practicantes con 16 calles; les siguen las ma- tronas con 9, los A.T.S. con 2 y una enfermera. Vemos reflejada en esta clasificación la especial significación del sentimiento popular hacia la matrona y el practicante, dos figuras tradicionales en los pueblos de España, con su toque un tanto romántico, a los que se han tributado multitud de homenajes por parte de las corporaciones locales y vecinos del medio rural. No sin razón, pues ellos se han ocupado incansablemente de atender las necesidades sanitarias de estas poblaciones con una entrega vocacional de servicio inigualable.

Sobre esta modalidad de reconocimiento público, el Colegio alicantino publicó en 2008 en sus órganos una comunicación animando a sus colegiados a proponer los nombres de compañeros y compañeras que consideren dignos de tal honor, con la siguiente salvedad: "Dichas propuestas deberán realizarse convenientemente razonadas y documentadas con los motivos por los cuales la persona en cuestión es merecedora de dar nombre a una calle y con un currículum de la misma."

\section{2.- Palmera dedicada a Enfermería (Elche, 2013)}

Elche dedicó una palmera a la Enfermería en reconocimiento a su aportación a la sociedad durante un acto celebrado en el marco de las XXIV Jornadas Nacionales de Enfermeras Gestoras/Supervisión de Enfermería, organizadas por la Asociación Nacional de Directivos de Enfermería (ANDE), que se celebraron en Alicante del 12 al 14 de junio de 2013. La dedicatoria fue posible gracias a las gestiones hechas ante el Ayuntamiento ilicitano por la presidenta de las Jornadas y vocal de ANDE en la Comunidad Valenciana, Remedios Yáñez, y el presidente del CECOVA, con la inestimable colaboración de Fernando Fernández Candela, subdirector de Enfermería del Hospital General Universitario de Elche. 


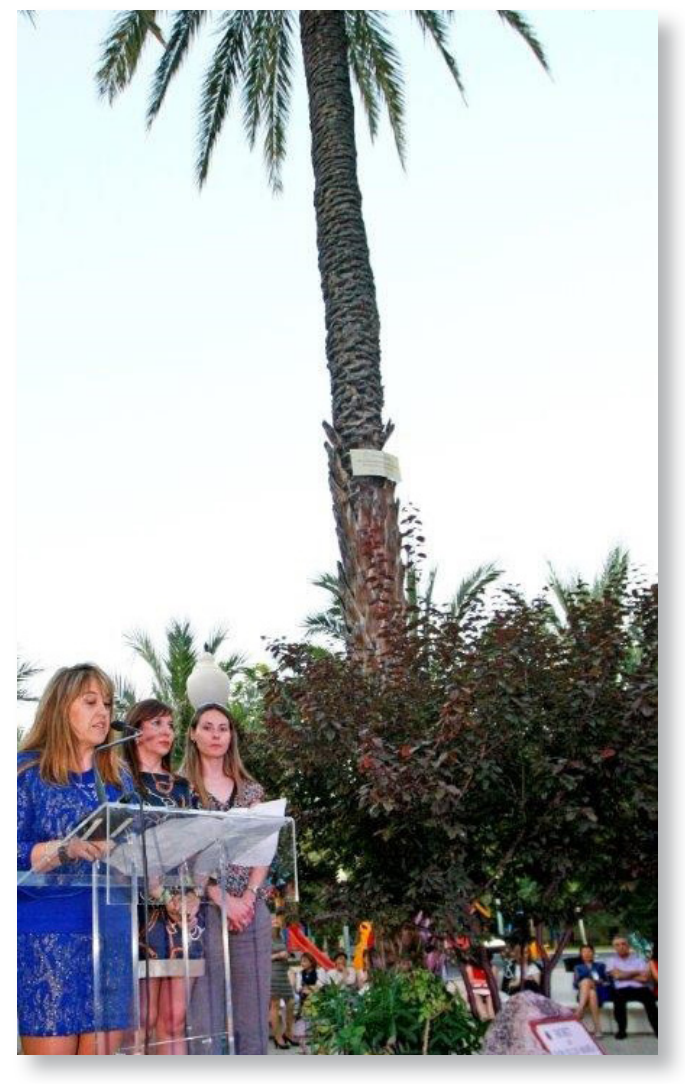

En Elche, dedicar una palmera a una persona, colectivo, institución o entidad es un acto singular y especialísimo que se remonta al último año de siglo XVIII. En 1900, tuvo lugar en Elche, concretamente en el Huerto del Cura, una reunión de celebres astrónomos europeos con motivo de un eclipse solar total que se produjo el 28 de mayo. Con motivo de tal evento, al día siguiente (29 de mayo) Elche dedicó una palmera al popular astrónomo francés Camilo Flammarion.

A partir de entonces, la ciudad viene otorgando tan alto y exclusivo honor a personajes ilustres, colectivos e instituciones que se han hecho acreedores a tan alto como exclusivo honor por su dignidad y méritos sobresalientes. Así, por ejemplo, José Canalejas, Gregorio Marañón, José María Pemán, Juan de la Cierva, Severo Ochoa, Miguel de Unamuno, Alfonso XIII, los
Reyes de España, el Tribunal de las Aguas de Valencia, entre otros, tienen una palmera dedicada.

Ahora, la profesión de Enfermería, ha quedado incluida en ese grupo notables con dedicatoria. Señalar que no llegan a cien las palmeras dedicadas en el legendario Palmeral ilicitano, el más grande de Europa, con cerca de medio millón de palmeras, solo superado en el mundo por algunos palmerales árabes. En la placa que se ha colocado en la palmera dedicada se puede leer el siguiente lema "A los profesionales de Enfermería. El valor de los Cuidados".

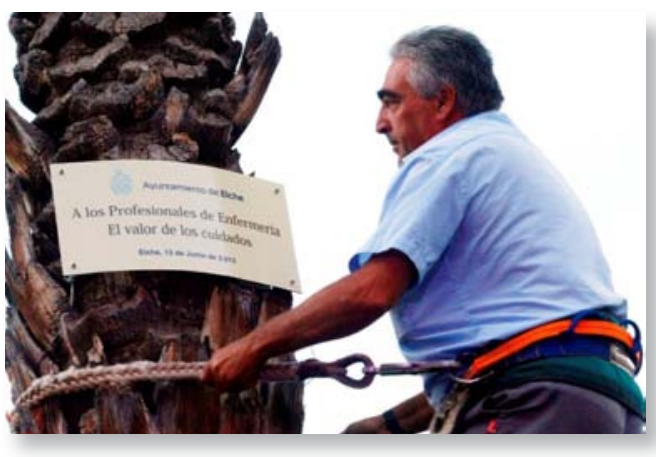

El Palmeral de Elche fue declarado Patrimonio de la Humanidad por la Organización de las Naciones Unidas para la Educación, la Ciencia y la Cultura (UNESCO) el 30 de noviembre de 2000. Así pues, en este sentido, Enfermería, en la porción que le corresponde, se señala como parte del patrimonio de la humanidad, símbolo del esfuerzo incansable de los miles de profesionales de Enfermería ilicitanos, alicantinos, valencianos y españoles en general. Hasta le fecha, es la única profesión que alcanza tan distinguida muestra de reconocimiento social en España.

\section{CONCLUSIONES}

1. Se han identificado, analizado y catalogado 7 monumentos dedicados a las enfermeras o a la Enfermería, de los cuales 5 no habían 
sido estudiados con anterioridad. Por lo que respecta a calles o espacios públicos urbanos dedicados hemos podido enumerar los existentes en la provincia de Alicante, gracias al catálogo realizado por el Colegio de Enfermería de aquella provincia, pero no hemos podido hallar datos a nivel nacional por no haberse realizado hasta la fecha ningún catálogo general que recoja las realizaciones de esta naturaleza existentes en España.

2. La acción de los Colegios de Enfermería para sugerir e impulsar ante las Corporaciones municipales la aprobación de erigir monumentos, dedicar calles o implementar realizaciones en honor de las enfermeras o de la Enfermería se ha acreditado como indispensable y decisiva. La gran mayoría de estas realizaciones se han debido a la iniciativa e impulso de los Colegios.

3. Salvo alguna excepción, desde el punto de vista de la semiótica, los monumentos hasta ahora erigidos en nuestro país comunican de modo coherente y efectivo su mensaje de reconocimiento social hacia la labor profesional de las enfermeras y la gratitud y consideración hacia la Enfermería en general.

4. La dedicatoria de una palmera del mundialmente famoso palmeral de Elche (Patrimonio de la Humanidad), homenaje a la Enfermería de la provincia de Alicante, tiene una especialísima significación al ser la única profesión en España que consigue tal honor.

\section{BIBLIOGRAFÍA}

- Ballesteros Álvaro, A. M., (2006) La Enfermería española y su historia en la filatelia. Temperamentum, (4): Disponible en <http://www.index-f.com/temperamentum/ tn4/t6245.php > Consultado el 6 de agosto de 2013

- Calvo Calvo, M.A. (1994) Análisis icnográfico de la pintura de Lucas Valdés "Asistencia a los sacerdotes en la enfermería”. Hiades (10):403-412

- Casas, M. F. Miralles, M. T. (2001) Monumento a las enfermeras de la Cruz Roja de Astorga. Enfermería Clínica
(4):161-165

- Guerra González, J. E. Historia de la Enfermería (2008). Reflejo de la Filatelia. Híades (10): 782-803.

- Luna Gálvez, S. (2004) La Enfermería en la filatelia. Híades (9): 465-499.

- Miralles Sangro, M. T. (2008) La Enfermería a través de los sellos. Ediciones DAE. Madrid

- Miralles, M. T.; Duran, M. (2005) La enfermera en el monumento madrileño (1908-1936). Index de Enfermería (51):65-69.

- Núñez Del Castillo, M. y Siles González, J. (2004a) Evolución de los cuidados enfermeros: Análisis icnográfico desde la perspectiva de Virginia Henderson. Cultura de los Cuidados. $1^{\circ}$ semestre, (15): 17-25.

- Núñez Del Castillo, M. y Siles González, J. (2004b) Tras las huellas de nuestros orígenes cuidadores. Cultura de los Cuidados. 2º semestre, (16): 14-19

- Núñez del Castillo, M., Siles González, J., Jurado Moyano, 1. (2008 a) Relación de ayuda a través de la historia: una aportación desde la perspectiva iconográfica. Cultura de los Cuidados. 1er. Trimestre. (23): 27-34.

- Núñez del Castillo, M (2008 b) Los cuidados de salud a través de la iconografía. Una aportación desde la perspectiva de la enfermería. Tesis Doctoral

- Santo Tomás, M. et al. (1996) Iconografía y enfermería: un instrumento para la investigación histórica. Index de Enfermería (16-17): 87-88.

- Santo Tomás, M. et al. (1997) Iconografía y Enfermería. Un instrumento para la investigación histórica. Index de Enfermería (19):13-16.

- Siles González, J. (1994 a) Fuentes Etnográficas e Historia de la Enfermería. Híades (10): 111-137.

- Siles González, J. et. al. (1994 b) La Enfermería a través del cine: un estudio histórico y transcultural. Híades (10): 761-780.

- Siles González, J. (1999) Historia de la Enfermería. Ed. Aguclara, Alicante:75-76. Alicante

- Siles González, J. (2009) Origen de la Enfermería en el cine: El género histórico-documental y biográfico. Cuaderns de Cine (4): 57-69.

- Siles González, J. (2011) Historia de la Enfermería. Ed. Difusión Avances de Enfermería (DAE, SL): 95. Madrid 